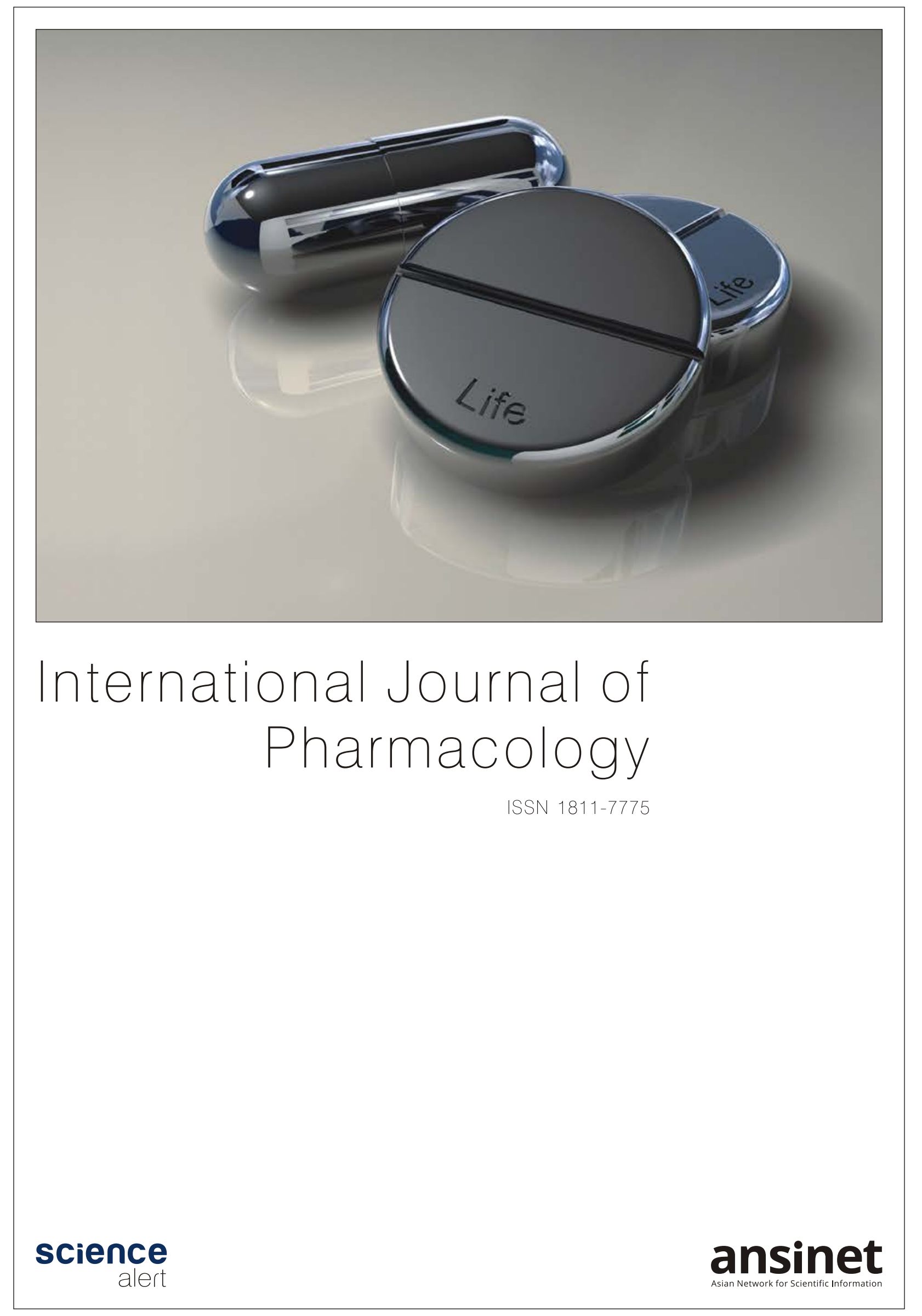




\title{
Enhancement of Nutraceutical Value of Table Eggs Through Poultry Feeding Strategies
}

\author{
${ }^{1}$ V. Laudadio, ${ }^{1}$ V. Lorusso, ${ }^{1}$ N.M.B. Lastella, ${ }^{2}$ K. Dhama, ${ }^{3} \mathrm{~K}$. Karthik, ${ }^{4}$ R. Tiwari, ${ }^{5}$ Gazi Mahabubul Alam and \\ ${ }^{1} \mathrm{~V}$. Tufarelli
}

${ }^{1}$ Department of Emergency and Organ Transplantation (DETO), Section of Veterinary Science and Animal Production, University of Bari 'Aldo Moro', 70010 Valenzano, Italy

${ }^{2}$ Division of Pathology,

${ }^{3}$ Division of Bacteriology and Mycology, Indian Veterinary Research Institute (IVRI), Izatnagar, Uttar Pradesh, 243 122, India

${ }^{4}$ Department of Veterinary Microbiology and Immunology, College of Veterinary Sciences and Animal Husbandry, Uttar Pradesh Pandit Deen Dayal Upadhyaya Pashu Chikitsa Vigyan Vishwa Vidyalaya Evum Go-Anusandhan Sansthan (DUVASU), Mathura (Uttar Pradesh)-281001, India

${ }^{5}$ Unit for the Academic Performance Enhancement, Office of the Vice Chancellor, University of Malaya, Wisma Research and Development (R and D), Jalan Pantai Baharu, 59990 Kuala Lumpur, Malaysia

ARTICLE INFO

Article History:

Received: December 27, 2014

Accepted: February 14, 2015

Corresponding Author:

Vincenzo Tufarelli,

Department of Emergency and Organ

Transplantation (DETO),

Section of Veterinary Science and

Animal Production, University of Bari

'Aldo Moro', 70010 Valenzano, Italy

\begin{abstract}
A B S T R A C T
A significant focus in the nutrition era has been oriented to nutraceutical and functional foods. The health promoting potential of such provisions is ascribed to nutrition and these constituents have useful properties playing important role for egg producers. The biological and nutraceutical importance of egg is often due to the active compounds. It holds various bioactive compounds having significant nutraceutical properties like antioxidant, antiallergenic, antiartherogenic, antimicrobial and cardioprotective. Antioxidants are important against many disorders like hypercholesterolemia and cardiovascular diseases. The growing attention on natural antioxidants has promoted researches in investigating new antioxidant sources having profitable prospective. Confirmation for the effectiveness of the enrichment of eggs with bioactive compounds by inclusion of plant-derived materials in the diet of egg-producing poultry has been reviewed. This review study aims to discuss the antioxidant potential of natural substances used to enrich the eggs and highlight the importance of eggs as potential nutraceutical food. The evidence for health-promoting effects of enriched eggs has also been included.
\end{abstract}

Key words: Eggs, nutraceutical value, enriched eggs, designer eggs, antioxidants, feeding, poultry, health

\section{INTRODUCTION}

The description of active compounds in food is an indispensable step in the validation process of such nutritional strategies and it is essential for the exact definition of "functional food" (Jezewska-Zychowicz, 2009). The discovery of active components contained in food daily consumed, is an essential step in the realization of a nutraceutical food having the capacity to prevent chronic disorders (Leoncini et al.,
2012). The term nutraceutical (a combination of nutrition and pharmaceutical) indicates a food component that provides health benefits, including the prevention of diseases. Consumers are progressively more interested in functional foods, therefore in present scenario they are extremely careful on their wellbeing as a result demands of beneficial foods worldwide growing. In spite of slight variations in overall nutritional content of eggs from country to country (mostly related to the variations in diet fed to the hens), eggs are 
widely recognized as naturally rich in proteins and a number of vitamins and minerals. The egg is often referred to as one of the original and natural functional foods. Nutritional claims allowed for regular eggs (standard diet fed to the hens) vary from country to country mostly due to regulations (Guyonnet, 2011).

Eggs provide a completely packaged, highly nutritious food including essential nutritional components (Laudadio et al., 2014). However, the uncertainties are related to the cholesterol level in eggs. It was reported by Gilbert (2000) that eggs result more healthier and valuable food when cholesterol content is reduced. Nevertheless, the cholesterol level derived from egg is much lesser than the cholesterol concentration synthesized by humans (Singh and Sachan, 2010). The interior components of egg can easily be transformed by poultry feeding practices (Laudadio and Tufarelli, 2011; Khan et al., 2012a). The eggs can also be improved thanks to additional nutrients such as selenium, vitamins B-group, vitamin $\mathrm{E}$ and particularly antioxidant compounds. Nevertheless, the fortification of different nutrients in egg is exclusively dependent on nutritional changes of laying hen diet (Ahmed and Abdelati, 2009; Singh and Sachan, 2010). This egg is moreover able to attract the market attention by varying their health status and interesting to a kind of the consumer who are available to spend for these changes in egg. Therefore, as need and production of enriched eggs increases, research is needed to establish their solidity and adequacy. Egg is a nutritive food rich in proteins and it is a cheap source of protein (Hasler, 2000). Altering the nutritive contents of the egg can thus help alleviating the problem of nutritional deficiencies in target population (Kassis et al., 2010). World bodies recommend for the intake of 3 servings of vegetables and 2 servings of fruits a day but this is not practically feasible in many countries which are developing. So there is a definite need for an alternative that can sort these problems (Dike, 2014). One should have a food item that is accepted by most of the people in the community, egg is one such food item that can be fortified with various nutrients. Egg is superior to animal meat in case of nutrients because animal meat contains more fat that can cause various health problems to human which include heart attack (Simopoulos, 1991).

\section{EGG AND ITS BENEFITS}

Egg is considered as the balanced diet that contains all nutrition of which major is contributed by protein. It also contains vitamins and minerals and can be considered as a low calorie diet. Very few sources supply vitamins like $\mathrm{K}$ and $\mathrm{D}$ to the human through diet and egg is one among them (Kassis et al., 2010). Egg also supplies a factor that is very crucial for the development of human brain which is choline (Herron and Fernandez, 2004). Production of egg Is easy now-a-days as poultry production has become an industry. Hence egg offers good quality nutrients at low cost and it is used in most household for baking, cooking etc. (Stadelman et al., 1995; Stadelman, 1999). Though it provides all nutrients that have a positive impact over human health egg yolk also contains cholesterol that can harmfully affect human health. Cholesterol content of egg is approximately $200 \mathrm{mg}$ which as per standards laid by America is just short by a hundred to meet the daily needs of a person (Weggemans et al., 2001). So, once a person crosses the limit of cholesterol intake, diseases affecting the heart haunt him (Howell et al., 1997).

Humans are always attracted towards nutrients that are available in less quantity in food items but that are very essential for healthy living. There are few in this list which includes vitamin $\mathrm{E}$, selenium, $\mathrm{n}-3$ fatty acids and carotenoids. These nutritive factors have important role in healthy living of humans and hence they are rightly considered by nutritionist to enhance these nutrients in various food stuffs (Surai and Sparks, 2001). Eggs usually contain higher level of saturated fatty acids that are harmful to human. Omega 3-polyunsaturated fatty acids (PUFA) are the good fats to human health, hence various attempts have been made to increase PUFA content in the egg yolk simultaneously decreasing the bad cholesterol content (Juturu, 2008). By altering the ration feed to poultry, scientists have tried to alter the fat content of the egg yolk. Attempts have been made to increase the $\alpha$-linolenic acid content of the yolk which can be converted into PUFA in human body (Hu et al., 1999). To achieve this plant sources like flaxseeds and linseeds that are rich in $\alpha$-linolenic acid are incorporated in poultry ration (De Lorgeril et al., 1994; Ferrier et al., 1995). A major drawback noted by this method is that the conversion of $\alpha$-linolenic acid to PUFA is not so effective. To negotiate this problem the best way to add stuffs that contain preformed PUFA which include fish oil (Leskanich and Noble, 1997). The problem noticed by addition of these oils has led to the fishy odour of the egg which is not accepted by many people (Van Elswyk et al., 1992). Eggs that are enriched with various essential nutrients are called as super eggs.

\section{ROLE OF THE ANTIOXIDANTS IN HUMAN HEALTH}

In last decade there is an increase of studies related to novel progresses in diseases prevention particularly the function of antioxidants and free radicals (ROS). Thus, it will be relevant to study the potential role of the ROS in health disorders and the antioxidants in its prevention (Pandithurai and Murugesan, 2014). It was reported a dangerous influence of ionizing radiation might be attributed to creation of ROS (Sohal and Weindruch, 1996; Devasagayam et al., 2004). Since then ROS and Reactive Nitrogen Species (RNS) have gained renown importance (Gilbert, 1981). In the scientific and medical literature the definition of 'free radical' is utilized in an ample sense and includes related reactive species such as 'excited states' leading to ROS production or those species resulting from free radical reactions. The ROS have been involved in many human disorders (Halliwell and Gutteridge, 1985).

The relation between ROS and disorders could be clarified using the Oxidative Stress (OS) concept (Celi, 2011). In 
animal healthy body, the of prooxidants formation as ROS and RNS are efficiently kept in control by different antioxidant defense levels (Devasagayam et al., 2004). Nevertheless, when it gets exposed to unfavorable physicochemical and environmental agents (pollutants, cigarette smoking, UV rays, radiation, toxic elements, over-feeding and diabetes), this delicately maintained balance is shifted in favor of pro-oxidants resulting in OS (Kilgour and Roberts, 2014).

Antioxidants are defined as substances neutralizing the free radicals (Powers et al., 2011). Nature has provided cells with enough defensive instruments against any damaging properties of free radicals: superoxide dismutase, glutathione peroxidase, glutathione reductase, thioredoxin and disulfide bonding are buffering systems in cells (Devasagayam et al., 2004). Because of capable antioxidant defensive methods are vital to slow down the OS, investigating for other antioxidants in disorders reduction has received much interest in the last decades. Important health benefits of natural and synthetic antioxidants like many vitamins, phenols and carotenoids present anti-cancer and anti-inflammatory properties. The antioxidants are able to neutralize free radicals and related events, take action at diverse phases. In fact, antioxidants proceed at the stage of repair, interception as well as prevention (Wojcik et al., 2010; Khan et al., 2012b; Rahal et al., 2014).

The vitamin C is a water-soluble free radical scavenger. Animals are not capable to synthezise ascorbic acid, so this complex must be supplied by diet, in particular with vegetable sources. The main natural sources of ascorbic acid are found in brussels sprouts, broccoli, grapes, kiwi fruits, cantaloupes, fruit, green or red pepper, strawberries, cabbage, kale. Daily dietary allowance was recommended to be $60 \mathrm{mg}$ (Jacob and Sotoudeh, 2002). It also has the ability to scavenge $\mathrm{OH}, \mathrm{H}_{2} \mathrm{O}_{2}$, $\mathrm{ROO}$ and $\mathrm{O}_{2}$ (Padayatty et al., 2006; Chen et al., 2008). Ascorbic acid revealed to act a key-role in the modulation of immunological processes, above all involving in the IL-18 production, a great inducer of the interferon- $\gamma$ (Kim et al., 2000).

The other significant scavenger of ROS in diet is greatly lipophilic vitamin $\mathrm{E}$, present in nature in many compounds as $\alpha, \beta, \gamma$ e $\delta$-tocopherols and $\alpha, \beta, \gamma$ e $\delta$ tocotrienols (Wojcik et al., 2010). Valuable source of tocopherols are nuts and the oil from vegetables (i.e., sunflower or wheat germ). The tocotrienols are all over in cereals and oils (wheat, barley, rice, barley, palm and bran oils). The alpha-tocopherol is the predominant form in diet that is known by hepatic alpha-tocopherol transfer protein and moved to blood and tissue (Traber, 2007). The $\alpha$-tocopherol is considered to have significant function in atherosclerosis prevention. It was found that high doses of alpha-tocopherol inhibited the platelets adhesion and aggregation and also expression of molecules adhesion on monocytes. Based on the role of vitamin $\mathrm{E}$ as antioxidant and that $\mathrm{OS}$ resulted in cancer genesis, it was supposed that vitamin E could have a role against cancer development. It was supported by many animal studies (Zhang et al. 2004; Dong et al., 2007).
Over 600 fat-soluble plant pigments (carotenoids) are available in fruit and vegetables, such as $\alpha$-carotene (yellow pepper, carrots, pumpkin, corn), $\beta$-carotene (alfalfa), lycopene, $\beta$-cryptoxanthin, lutein and zeaxanthin (spinach, broccoli, lettuce, corn) (Voutilainen et al., 2006). The $\beta$-carotene is the main vitam in A precursor (namely pro-vitam in A) and to date it represents the pigment widely studied. In plasma, carotenoids are associated either with low density lipoproteins ( $\beta$-carotene, lycopene) or with high density lipoproteins (lutein and zeaxanthin). Since $\beta$-carotene is capable to stop cancer cells and apoptosis and in addition, successfully quench $\mathrm{O}_{2}$ and in a straight line repress the oxidation of low density lipoproteins, significant consideration is focused on beta-carotene function in prevention of cancer as well as cardiovascular diseases (Krinsky and Johnson, 2005). Lately, more consideration has been paid to antioxidant role of lycopene, in fact it was found that lycopene may be involved in risk reduction of many health disorders (Wojcik et al., 2010). In contrast with plants and microorganisms, animals are unable to synthesize lycopene. Lycopene predominates in trans form, the most stable form, in tomato, however the cis form is considered the most bioavailable form in blood and tissue (Unlu et al., 2007). Lycopene has been evaluated as a chemopreventive compound in animal trials due to its function of inhibitor many diseases and disorders more than $\alpha$ and $\beta$-carotene (Levy et al., 1995).

The identification of polyphenols, particularly flavonoids are classified into six subgroups such as flavones, isoflavones, flavonos, flavanones, anthocyanidins and catechins (Pal and Verma, 2013). Given that polyphenols are rich dietary antioxidants, polyphenols have become indispensable for human and animal, principally as anti-cancer and anti-inflammatory agent. Many researches on the polyphenols anti-inflammatory and anticancer properties contained green and black teas have demonstrated the probable defensive act in diseases. The positive properties of polyphenols were demonstrated by studies showing that this compound reduce carcinogenesis in many tissues (Lambert et al., 2005). Moreover, it was reported that the major resource for anthocyanins is represented by red grape skin, elderberry, purple carrot, red cabbage and specially these molecules from purple carrot have valuable antioxidant property (Poudyal et al., 2010).

The most promising and the most frequently investigated polyphenol exhibiting beneficial role in health, is the resveratrol in trans form, polyphenol very present especially in red grape, peanuts and various berries (Smoliga et al., 2011). During the last years, its overabundance of valuable health-related characteristics such as cardiovascular and protective properties were newly discovered as an important dietary supplement (Goswami and Das, 2009; Lin et al., 2013). Given that OS is an important cause of increased risk of cardiovascular diseases, the treatment of many health disorders through the utilize of natural antioxidant sources, including ascorbic acid tocopherols, carotenoids and polyphenols, an 
increase of attention in this era was received. In fact, it is well known that the vegetables and fruit intake daily and regularly consumed decrease and prevent significantly the development of health problems (Pham-Huy et al., 2008).

\section{ANTIOXIDANTS IN EGGS}

Egg is considered a perfect natural food that has been consumed for centuries worldwide. Although egg contains all the indispensable nutrients for life, its consumption in several areas has reduces due to the public insight on its high cholesterol level (Nimalaratne et al., 2011). The antioxidant content of egg is almost nill and a fraction is found in egg yolk. So fortifying egg with antioxidant can enhance its quality which can be achieved by altering the ration in poultry feed (Carlsen et al., 2010). On the other hand, present data report that there was no full correlation between egg intake and plasma cholesterol concentrations as stated by Qureshi et al. (2007). Egg-yolk is a valuable source of many compounds significant for humans as well as animal wellbeing. It was well demonstrated that the diet supplied to laying hens has direct influence to yolk qualitative traits. By changes in diet, specific molecules having positive health effects can be incorporated in the egg-yolk (Kuhnle et al., 2008). To date, different investigations stated that active molecules in feed can be shifted from hens diet to egg-yolk. Among compounds, both lutein and zeaxanthin resulted the most widely studied molecules in eggs. These help to reduce macular degeneration related to the age either filtering harmful light blue and/or as antioxidants (Chung et al., 2004). Isoflavones from soybean was found to contain phytoestrogens having possible health effects and they were detected in yolks (Kuhnle et al., 2008). Phenolic compounds usually contained in cereals, fruit and many vegetables are significant antioxidants, suggesting to occupy a defensive function in the various disorders of chronic nature (Liu, 2007). All the natural phenolic compounds derived from a common biosynthetic pathway, incorporating precursors from the shikimate and/or the acetate-malonate pathways (Colombo et al., 2014).

Up till now, few data is existing on the possible polyphenols in poultry eggs. Hens are well known to be able to 'bioconvert' health-related molecules from diet to egg. Both wheat and maize are valuable food/feed ingredients in diet containing antioxidants. Since these are main feed components for poultry in Canada, the objectives of a study conducted by Nimalaratne et al. (2011) were to characterize the presence of novel phenolic compounds in egg yolk, total antioxidant capacity of yolk extracts and to evaluate the effect of cooking methods on their content and activity. The results of this study suggested that eggs contain important levels of antioxidants as well to its renowned nutrients. Thus, consuming cholesterolrich food such as eggs was once indicated as a potential causing factor for cardiovascular disorders and the findings might even give rise to a paradigm change in nutritional eggs evaluation.

\section{ENRICHED EGGS}

Food stuffs that provide nutrients above the basic requirement are called as functional foods (Bech-Larsen and Grunert, 2003). Eggs fortified with various nutrients are also classified in this category. A large number of scientific trials into the feeding of enriched diets to laying hens have been carried out, demonstrating the levels of feed supplementation required to give a significant increase in the eggs. Many trials aimed to demonstrate the helpfulness and possible effects of dietary enrichment on productive traits in layers (Kaminska etal., 2001; Bean and Leeson, 2003; Mazalli etal., 2004; Jia et al., 2008), eggs' qualitative parameters (Niemiec et al., 2001; Ajuyah et al., 2003; Laudadio et al., 2014), sensorial assessment (Nash et al., 1996; Rymer and Givens, 2005) and health related effects (Lewis et al., 2000; Payet et al., 2004; Laudadio and Tufarelli, 2010). Moreover, with nutritional enrichment of laying hen diets it is not only consumers who benefit but also the producers in terms of bird health, performance and even egg quality.

A large number of scientific trials into the feeding of enriched diets to laying hens have been carried out, demonstrating the levels of feed supplementation required to give a significant increase in the eggs. Focus has been given mainly to improve the omega 3 fatty acid content of egg yolk and also to reduce the cholesterol level of the yolk. Researchers found that addition of copper sulphate pentahydrate to the poultry ration has reduced the cholesterol content (Liu et al., 2010). Addition of garlic paste to the poultry ration has also brought down the cholesterol content (Chowdhury et al., 2002).

Enriched eggs are defined as eggs having different characteristics compared to common eggs. So-named designer eggs represent a significant part of all shell eggs in many countries and these eggs are enriched in omega- 3 fatty acids which benefit human nutrition (Leeson and Caston, 2003; Sawant et al., 2012). In fact, the most available enriched eggs are those with changed fat level. However, modified fat content are marketed as a low cholesterol content, few saturated fatty acids, high levels in omega-3 fatty acids, high vitamin B as well as iodine (Singh et al., 2012). During the past decades, Sim Jany and their colleagues in Canada have developed designer eggs high in omega-3 fatty acids and antioxidants and subsequently they patented these eggs as Sim's designer-eggs. Later, Farrell (1998) in Australia produced a different modified egg containing significant levels of folate and iron, very useful for people with anemia. Canadians Leeson and Caston (2004) developed eggs which was pretty high in lutein level as compared to the common eggs. These modified eggs operate as a tonic for retina helping to prevent ocular degenerations. Various companies also markets eggs that are fortified with omega 3 fatty acids. Nutriplus is the brand name of the egg with omega 3 fatty acid and the producer is also Nutriplus. This is available in Malaysia (Lau et al., 2013). Some workers have also used 
marine algae Nannochloropsis oculata to poultry diet to get altered fatty acid level in the egg yolk. By addition of algae there is PUFA production in yolk and also alteration in the carotenoid content in the egg yolk (Fredriksson et al., 2006).

\section{NUTRITIONAL STRATEGIES FOR EGG ENRICHMENT USING ANTIOXIDANTS}

The most well-known antioxidant utilized in animal nutrition is the alpha-tocopherol which is simply deposited in egg-yolk (Singh et al., 2012; Skrivan and Englmaierova, 2014). Nevertheless, other available compounds and molecules in eggs may also prevent oxidation, as Se and carotenoids. Antioxidants are deposited in yolks in function of dietary inclusion level. Enriching eggs with alpha-tocopherol or carotenoids may be obtained in an ample variety and moreover without negative effects on qualitative characteristics of eggs. Carotenoids of synthetic origins frequently supplemented to the poultry diet represented almost the total pigments in egg-yolk. Conversely, modifying egg using $\mathrm{Se}$ is quite more difficult because of high concentration of Se in food and feed can be toxic for both humans and animals (Pophaly et al., 2014). However, no harmful impact of antioxidants on egg quality parameters are to date reported.

Enriched vitamin E eggs can be obtained with high level of vitamin-E when compared to standard egg by supplying hens with rations containing high vitamin $\mathrm{E}$ level (Leeson and Caston, 2004). Higher levels of vitam in E may be obtained by supplementation of ingredients in form of natural sources. Supplementation with vitamin-E in diet for laying hens determine the following positive effects (Singh et al., 2012): reduction of blood free radicals; decrease of cancer risk thanks to reduction of free radicals formation; reduction of the heart risk acting as antioxidant; delay of the development off-odors since vitam in $\mathrm{E}$ acts as high-quality antioxidant.

The most frequent methods to enrich eggs with both vitamins and minerals is to use high levels in the diet and it resulted a extremely useful practice to produce enriched eggs. Enriching eggs with vitamin $\mathrm{E}$ is a very accepted practice because of its antioxidative properties for all species (Mohiti-Asli et al., 2008). However, to date few trials aimed to evaluate the transfer of vitamin $\mathrm{E}$ from diet to eggs during the second laying production phase utilizing old molted laying hens are available. The researchers are imperative for producers because of significance of maintenance egg value and for improvement of nutraceutical properties of eggs. In a trial, Gjorgovska et al. (2012) used laying hens fed with basal diet supplemented with vitamin $\mathrm{E}$ and selenium as control group, while the birds from the experimental treatments were fed with higher dietary level of vitamin $\mathrm{E}$ in two different increasing concentrations. The vitamin E level in egg-yolk increased in laying hens when fed higher vitamin $\mathrm{E}$ level. The higher levels of vitamin $\mathrm{E}$ in diet determined an increase of egg production and laying duration. Moreover, a similar tendency was reported increasing Se level in the diet (Gjorgovska et al., 2012).
Another research was conducted to evaluate the effect of dietary vitamin $\mathrm{E}$ levels on metabolic traits in heat stressed hens (Yardebi and Turkay, 2008). The study used Leghorn laying hens which were assigned to two groups and initially subjected to the same environmental conditions. Diets were based on standard layer rations with different increasing levels of dietary vitamin E. Before, during and after heat stress exposure blood samples were collected from birds. Significant increases in plasma malondialdehyde, erythrocyte $\mathrm{MDA}$, glutathione peroxidase, catalase, superoxide dismutase and MDA concentration in egg yolk and a reduction in plasma vitam in $\mathrm{E}$ were observed in groups during heat stress. Quality parameters in eggs were also reduced in the experimental group during heat stress. Dietary higher levels of vitamin $\mathrm{E}$ improved some of metabolic consequences determined by heat stress; moreover, there was no verification of advantageous influence on egg produced under heat stress within Se levels studied.

Currently, Se enriched eggs are existing worldwide. Among countries, Russia results the most advanced country for the Se enriched eggs production of (Fisinin et al., 2009). As expected, the cost of the Se enriched eggs is higher compared to a standard egg. Nowadays, the Se level in egg may be simply changed by supplementing high levels of Se feeds to poultry (Surai and Fisinin, 2014). The Se is one of the most essential nutrient because it is involved in very crucial roles in both humans and animals (Tufarelli and Laudadio, 2011). The Se enriched eggs were for first time obtained by the Scottish Agriculture College in 1998 (Surai, 2000) supplementing organic Se from yeast to diets fro laying hens. The Se occurs in the egg mostly in the form of selenomethionine. As well known, $\mathrm{Se}$ is a fundamental component of many bioactive Se-proteins important for wellbeing coming from various ingredients such as cereal grains, meat from poultry or fish (Hattingh et al., 2008). It was demonstrated that Se helps in: Arthritis reduction, cancer (Papp et al., 2007), cystic fibrosis, immunodeficiency, muscular dystrophy, diabetes (Surai, 2000); decreasing the risk of DNA damage associated with cancer; Se improve blood fluidity providing protective factor against cardiovascular diseases (Abdulah et al., 2006); Se may offer a valuable way through rising antioxidant protection (Venardos et al., 2007); Se enriched eggs can decrease the osteoporotic hip fracture risk (Zhang et al., 2006).

The effects of inclusion level of $\mathrm{Se}$ (as Se yeast or sodium selenite) in diet for hens, on egg performance, qualitative traits and yolk Se level was evaluated by Gjorgovska and Filev (2010). This trial was conducted using molted hens. The control group received a basal diet with Se from sodium selenite and the other groups with two different levels of Se from sodium selenite and Se yeast, respectively. From findings, the eggs produced were higher in hens fed Se yeast in diet. The egg qualitative traits were superior hens fed supplemental Se. The Se concentration in yolk was higher in laying hens fed with higher level of Se. Thus, it was concluded that Se level in diet may have an important effect on egg productive performance and some egg qualitative traits as well as on egg yolk Se concentration. 
Another experimental trial conducted by Invernizzi et al. (2013) evaluated the bioavailability of Se yeast in diet for laying hens and the effects on productive traits, egg qualitative parameters as well as tissue Se evaluation. Laying hens (ISA Brown) were divided into three dietary groups as follow: A control group fed a basal diet containing $0.11 \mathrm{mg} \mathrm{Se} \mathrm{kg}{ }^{-1}$; a basal diet plus inorganic Se; and a group fed a basal diet containing organic Se (yeast). Hen's productive traits were not influences by Se inclusion, in spite of the Se source. Egg qualitative parameters were higher in hens fed diets containing Se compared to control treatment. Breast, liver and skin Se concentrations were higher in birds fed organic Se while kidney Se level was higher in hens fed inorganic Se. Eggs from $\mathrm{Se}$ yeast had more $\mathrm{Se}$ contents than inorganic Se. Metabolites in blood were not influenced by Se typology. A high Se concentration was reported in egg and breast from hens fed organic Se. As result, Se enriched eggs and muscles from Se yeast in laying hens diet enhanced the antioxidant status.

Many studies have addressed the possibility of antioxidants supplemented in diet of laying hens, as vitamin $\mathrm{E}$ and $\mathrm{Se}$, to reduce cholesterol levels and to increase the amount of polyunsaturated fatty acids. A study conducted by Sujatha and Narahari (2011) using laying hens evaluated the effects of designer diets enriched with omega- 3 and antioxidants from natural ingredients on egg yolk quality. The birds fed diets as follow: Control (without enrichment); a diet containing flaxseeds, vitamin $\mathrm{E}$ and spirulina; a diet containing fish oil, organic Se and spirulina and a diet containing flaxseed, fish oil, vitamin E, organic Se and spirulina. All three enriched diets improved yolk carotenoids and omega- 3 concentrations with reduction in SFA concentrations with significant changes in oleic acid in yolk fat. The three diets also decreased the yolk cholesterol. Thus, adding $\mathrm{Se}$ and vitamin $\mathrm{E}$ in diet synergistically increased omega-3 deposition in yolk.

Selenium and vitamin $\mathrm{E}$ are important elements of the antioxidant system to reduce lipid oxidation. In omega-3 eggs, omega-3 PUFA are susceptible to oxidative damage during cooking and storage. A research from the University of Alberta (Canada), focused on the stability of n-3 PUFAs enriched eggs fortified with vitamin $E$ and/or organic selenium following cooking and storage (Ren et al., 2013). Both vitamin $\mathrm{E}$ and organic selenium offer protective effects by reducing oxidation in raw eggs, allowing a better $\omega-3$ enriched egg to be marketed. A mix of antioxidants was beneficial for stabilizing long chain $\omega-3$ PUFAs and is something for the industry to consider as they improve this product.

Carotenoid enriched eggs: Eggs fortification with carotenoid is the novel idea in the area of the designer eggs. The pigment enriched eggs looking attractive to people due to its gorgeous nature of more deep yellow coloration. Among carotenoids, canthaxanthin typically used for pigment production of enriched yolk by feeding hens with diets high levels of this pigment (Grashorn and Steinberg, 2002). However, there are quantities of other pigments that can be utilized for egg fortification (Singh et al., 2012). These carotenoid pigments are naturally obtained from many natural sources (Nezhad et al., 2008). For example, blue green algae is the another resource of carotenoids which is essentially high in protein but also supplies specific pigments such as spirulina and it can be used for improvement of the carotenoids level in yolk (Singh et al., 2012). Usually carotenoids in poultry eggs are of hydroxyl molecules named xanthophylls (Moeller et al., 2000), while lutein and zeaxanthin are the two most frequent xanthophylls reported in egg-yolk. The positive effect of pigment in the egg-yolk (Kang et al., 2003; Singh et al., 2012) including: the prevention of macular degeneration, the improvement of the yolk colour; the pigment operates as antioxidant compound.

A study from Japan was conducted to investigate the effects of two dietary lutein sources, such as the commercial lutein and the emulsified crude extract of spinach containing lutein, on the lutein transfer into egg yolk as well as the antioxidant defense system in the liver of laying hens (Jang et al., 2014). White Leghorn hens were assigned to a basal $\operatorname{diet}(\mathrm{CON})$ and that supplemented with a commercial lutein (LUT, $40 \mathrm{mg}$ lutein $\mathrm{kg}^{-1}$ of diet) and the crude extract of spinach dissolved into oils with lecithin (ECE, $40 \mathrm{mg}$ lutein $\mathrm{kg}^{-1}$ of diet) for five weeks. From findings, there was no difference in body weight and relative live weight among dietary groups. The concentration of egg yolk lutein and color increased in the LUT and ECE groups compared with the CON group. The LUT group showed a higher yolk lutein and much a lower variability of average yolk lutein content. Moreover, the dietary supplementation with lutein and the emulsified crude extract of spinach to laying hens resulted in significant increase in the content of egg yolk lutein and yolk color, indicating that both supplements may potentially be applicable for the production of egg-enriched lutein in laying hens. Recently, Benakmoum et al. (2013) aimed to evaluate the extent of enrichment of egg yolk with carotenoids and phenols through feeding sun dried tomato peels. Tomatoes are usually associated to the Mediterranean diet, linked with low risk of coronary diseases. Lycopene represents the main carotenoid in tomatoes and their byproducts, considered as its significant dietary source in human diet (Shi and le Maguer, 2000). Lycopene (all trans form) is attached to tomatoes membranes and has no provitamin A properties, in fact the long conjugated double chain renders its antioxidative activity of importance to human health (Unlu et al., 2007). However, heating and cooking can transform the trans double bonds to cis, leading to a more absorbed form. Tomato byproducts and particularly peels, have attracted large interest in nutritional aspects of both human and animal since they are valuable sources of natural antioxidants mostly in form of carotenoids as well as phenols. In a study conducted by Benakmoum et al. (2013), Dried Tomato Peels (DTP) were tested in hens at levels of $0,40,70$, 100 and $130 \mathrm{~g} \mathrm{~kg}^{-1}$ diet, for 26 days. Egg yolk from DTP-enriched diets, had lower amounts of cholesterol $\left(14-17 \mathrm{mg} \mathrm{g}^{-1}\right)$ and triglyceride $\left(188 \mathrm{mg} \mathrm{g}^{-1}\right)$ as with that of 
control group. Following DTP-enriched diets, total phenols was 2.0-3.6-fold higher, $\beta$-carotene 1.7-2.7-fold higher and lycopene increased between 26.5 and $42.8 \mu \mathrm{g} \mathrm{g}^{-1}$, thus the optimal supplementation level resulted DTP at $7 \%$.

The poultry eggs are considered a valuable source of nutrients, in particular protein, lipid, vitamins and minerals and many other bioactive compounds having antioxidant properties (Kovacs-Nolan et al., 2000; Nimalaratne et al., 2011). However, there are few available information on the consequence of cooking methods and digestion on antioxidant activities of egg. As a high-protein food product, liberation of many peptides in human gastrointestinal tract might further improve the antioxidant activities and consequently determine positive influences to health (Remanan and $\mathrm{Wu}, 2014)$. The objective of a recent study was to evaluate the influence of cooking methods and on antioxidant activities in egg (Remanan and $\mathrm{Wu}, 2014$ ). The results suggested that fresh egg yolk has higher antioxidant activity than fresh egg white and whole eggs and compared to boiled or frying eggs. Thus, the Authors highlighted the importance of egg as dietary antioxidants.

An overview of the strategies for enriching the nutraceutical value of the eggs with emphasis on the use of antioxidants and natural substances including herbs for production of designer and functional eggs as well as their health-promoting effects highlighting the importance of eggs as potential food are presented in Fig. 1.

\section{HERBAL ENRICHED DESIGNER OR FUNCTIONAL EGGS}

As previously mentioned, the egg is often referred to as one of the original and natural functional foods. Numerous studies have demonstrated that variations in rations fed laying hens can greatly impact the level of nutrients such as vitamins, minerals, omega-3 polyunsaturated fatty acids (PUFA) and lutein (Schiavone and Barroeta, 2011). Some studies indicate that organic eggs do not have much difference in this cholesterol content compared with conventional egg. Omega 3 fortified eggs by feeding oils have shown higher PUFA (Samman et al., 2009). Multiple nutritional enhancements of eggs can easily be achieved commercially (Bourre, 2005), using the most natural way (feeding the hens) as the means to enrich eggs in nutrients. Egg is the most effective vehicle for incorporating different health-promoting molecules (Leeson and Caston, 2004). Herbs enriched egg can be produced by the incorporation of active compounds such as lutein, allicin, taurine, betaine, lumiflavin, eugenol and other molecules, according to the ingredients fed to poultry (Table 1). Furthermore, this egg had lower cholesterol in yolk $(-25 \%)$ when compared to standard egg. Consuming these eggs by humans resulted a considerable decrease in blood triglycerides concentrations, increased in high density lipoproteins, enhanced immunological parameters and improved haematocrit. The bioactive compounds in these nutraceutical eggs and the role in both humans and animals wellbeing are summarized in Table 1. These type of herbal enriched designer eggs were build up by Narahari et al. (2004) in India. Recently, Raj et al. (2013) investigated the value addition of eggs with use of natural supplements in poultry feed such as garlic, fenugreek and bay to validate the reduction in cholesterol in egg-yolk. It was found that supplementing of diet with garlic resulted in high egg-yolk hypolipidemic activities. Conversely, supplementing diet with fenugreek and bay determined a production of eggs with significant content of vitamin E and Se (Raj et al., 2013). Thus, the tested herb supplements produced enriched eggs in omega-3 PUFA having positive effects to wellbeing. Consequently, these studies demonstrated that egg having enriched nutritional characteristics may be produced thanks to changes in laying hens' diet. Similarly, another study was conducted in white leghorn layers by feeding with holy basil, pearl millet, flaxseed and sardines. Oils from all these herbal leaves were fed to different group of chicken and their effect on various parameters in egg production was noted (Kirubakaran et al., 2011). At the end of the trail it was found that chicken fed with flaxseed and sardine oils produced eggs with higher level of polyunsaturated fatty acids in their yolk. This increase in polyunsaturated fatty acid is attributed to oils that are fed to them as they are usually rich in PUFA. Flaxseed and holy basil feeding increased $\alpha$-linolenic acid in the egg yolk (Kirubakaran etal., 2011). Supplementation of thyme has been found to improve the antioxidant property of egg yolk (Gopi et al., 2014).

Table 1: Natural sources in enriched eggs and role for human and animal well being

\begin{tabular}{|c|c|c|}
\hline Herbs* $^{*}$ & Active ingredient in herbs & Benefits in relation to human health \\
\hline Turmeric powder & Flavonoids compounds & Antimicrobial, antioxidant \\
\hline Garlic, onion and their leaves & Allicin, Allyl sulfide & Reduce LDL cholesterol, anticarcinogenic properties \\
\hline Sugar beer, grape pulp & Betaine & Decrease plasma homocysteine which ruptures arterial walls \\
\hline Alfalfa, marigold petals, red pepper, spirulina & Carotenoid pigments & Antioxidant, anticarcinogenic \\
\hline Basil leaves & Eugenic acid, Eugenol & Immunomodulatory properties \\
\hline Marigold petals, bay & Lutein & Antioxidants, improves vision \\
\hline Tomato pomace, grape pulp & Lycopene & Decrease LDL cholesterol, antioxidant, anticarcinogenic \\
\hline Citrus pulp & Nirangenin & Reduce LDL cholesterol \\
\hline Flaxseed, canola, fish, oils, insects, worms & n-3 PUFA & Decrease LDL, hypertension, angina, atherosclerosis \\
\hline Seeds, legumes, weeds, fenugreek & Phytosterols & Increase HDL, decrease blood sugar \\
\hline Fenugreek, spices & Quercitin, Lutein, Citogenin & Induce insulin secretion, antimicrobial and tonic activity \\
\hline Brewery waste, yeast, fermented products & Statin & Reduce LDL cholesterol \\
\hline Broccoli, cauliflower, cabbage, radish leaves, waste & Sulphoraphane & Anticarcinogenic and antioxidant properties \\
\hline Bran & Tocotrienols & Decrease LDL cholesterol \\
\hline Milk, eggs, meat products & Taurine & Prevent atherosclerotic \\
\hline
\end{tabular}

*Adapted from Narahari et al. (2004) and Singh et al. (2012) 


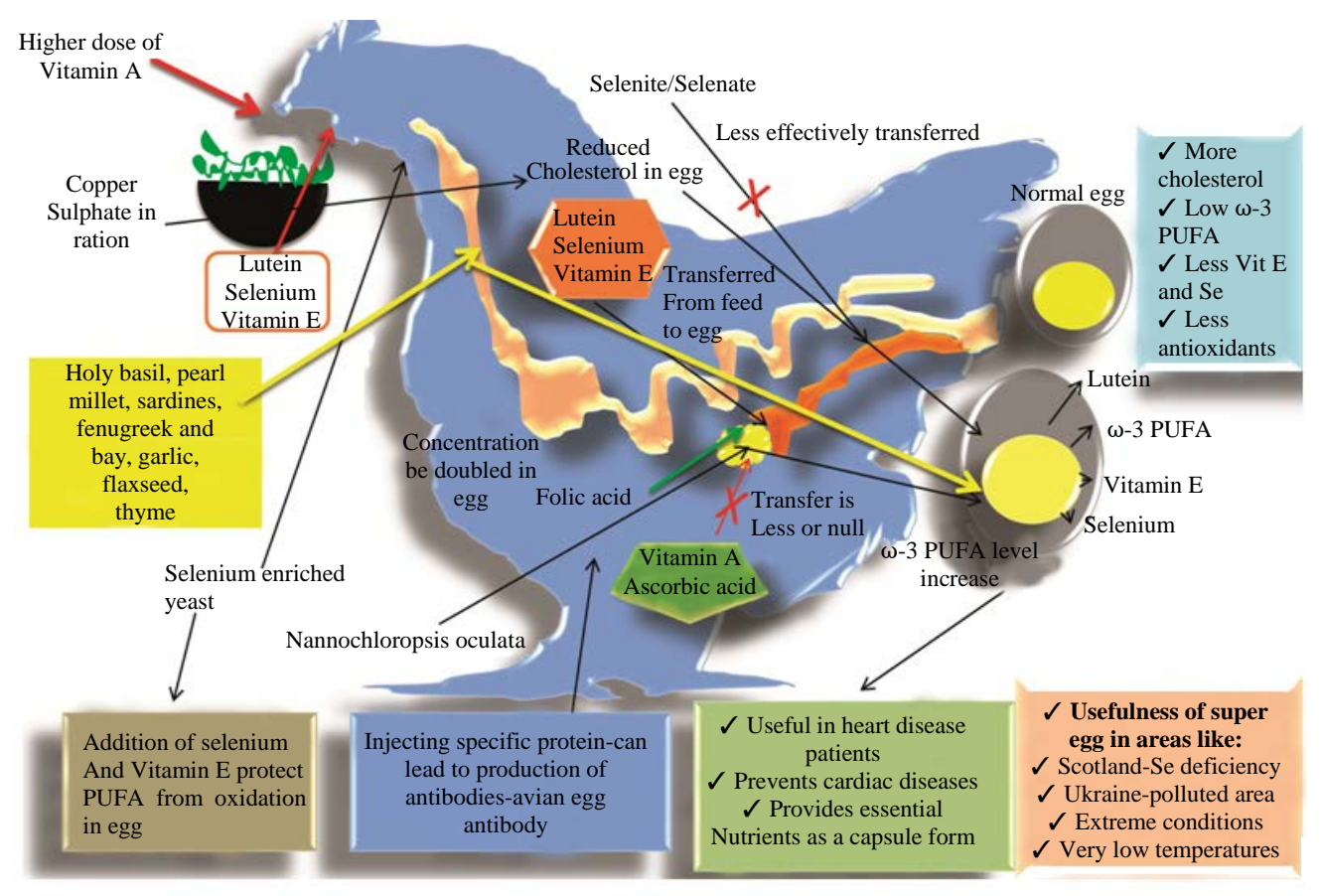

Fig. 1: An overview of enriched nutraceutical eggs and their health-promoting effects

\section{CONCLUSIONS}

The global egg production over the past decade has grown at fast pace in parallel with the demand for more eggs and animal proteins. People recognized more and more the health positive effects given by the level and value of proteins and other nutrients in eggs. The concern about cholesterol in spite of the lack of scientific validity continues to restrict consumption of eggs for some consumers. Several countries that are in developing stage and face crisis for supplying good nutritious food for the humans need some functional foods. Fortified or designed eggs with various nutrients can serve the purpose to support their such needs. Much work has to be carried out in order to help the people in need of this useful technology. Specialty eggs and egg products should develop more and more share of the global market as these products address some specific needs expressed by consumers. Experience and evidence showed that it is possible to create functional, enriched eggs to help correct dietary deficiencies. For example, one selenium-enriched egg can deliver approximately $50 \%$ of the recommended daily allowance and omega-3 eggs can deliver DHA and EPA in place of oily fish. Enriched eggs offer a way to increase the levels of health-promoting micronutrients, without significantly changing eating habits. Consumers buy, cook and eat eggs in the same way, just simply having to choose an enriched brand. Eggs can be marketed well as a functional food as they are increasingly seen to be part of a healthy diet. Consumer awareness of the health benefits of DHA and selenium, in particular, means that they are ideal candidates for enriching eggs. Working with several micronutrients may increase their marketability, as well as providing effective tools for brand promotion. By giving injections of protein of interest it is possible to design eggs with protective antibodies (avian egg antibodies) produced against a particular pathogen. This technology of designer eggs can be used with greater potential once it is studied well.

\section{ACKNOWLEDGMENTS}

Authors of the manuscript thank and acknowledge their respective Universities and Institutes.

\section{REFERENCES}

Abdulah, R., H. Koyama, K. Miyazaki, M. Nara and M. Murakami, 2006. Selenium supplementation and blood rheological improvement in Japanese adults. Biol. Trace Elem. Res., 112: 87-96.

Ahmed, M.E. and K.A. Abdelati, 2009. Effect of dietary graded levels of Leucaena leucocephala seeds on layers performance, egg quality and blood parameters. Int. J. Poult. Sci., 8: 475-479.

Ajuyah, A.O., G. Cherian, Y.W. Wang, H.H. Sunwoo and J.S. Sim, 2003. Maternal dietary fatty acids modulate the long chain $n-6$ and $n-3$ polyunsaturated fatty acid status of broiler cardiac tissue. Lipids, 38: 1257-1261.

Bean, L.D. and S. Leeson, 2003. Long-term effects of feeding flaxseed on performance and egg fatty acid composition of brown and white hens. Poult. Sci., 82: 388-394. 
Bech-Larsen, T. and K.G. Grunert, 2003. The perceived healthiness of functional foods: A conjoint study of Danish, Finnish and American consumers' perception of functional foods. Appetite, 40: 9-14.

Benakmoum, A., R. Larid and S. Zidani, 2013. Enriching egg yolk with carotenoids and phenols. World Acad. Sci. Eng. Technol., 7: 199-203.

Bourre, J.M., 2005. [New multi-enriched natural egg: Exceptional nutrient content, especially in omega-3 fatty acids, vitamins, minerals and carotenoids]. Med. Nutr., 41: 116-134, (In French).

Carlsen, M.H., B.L. Halvorsen, K. Holte, S.K. Bohn and S. Dragland et al., 2010. The total antioxidant content of more than 3100 foods, beverages, spices, herbs and supplements used worldwide. Nutr. J., Vol. 9. 10.1186/1475-2891-9-3

Celi, P., 2011. Biomarkers of oxidative stress in ruminant medicine. Immunopharmacol. Immunotoxicol., 33: $233-240$.

Chen, Q., M.G. Espey, A.Y. Sun, C. Pooput and K.L. Kirk et a l., 2008. Pharmacologic doses of ascorbate act as a prooxidant and decrease growth of aggressive tumor xenografts in mice. Proc. Natl. Acad. Sci., 105: 11105-11109.

Chowdhury, S.R., S.D. Chowdhury and T.K. Smith, 2002. Effects of dietary garlic on cholesterol metabolism in laying hens. Poult. Sci., 81: 1856-1862.

Chung, H.Y., H.M. Rasmussen and E.J. Johnson, 2004. Lutein bioavailability is higher from lutein-enriched eggs than from supplements and spinach in men. J. Nutr., 134: 1887-1893.

Colombo, M.L., C. Falciola, S. Maffe and F. Davanzo, 2014. Beneficial properties of plants and their derived extracts on the cardiovascular system. Nutrafoods, 13: 93-101.

De Lorgeril, M., S. Renaud, N. Mamelle, P. Salen and J.L. Martin et al., 1994. Mediterranean $\alpha$-linolenic acid-rich diet in secondary prevention of coronary heart disease. Lancet, 343: 1454-1459.

Devasagayam, T.P., J.C. Tilak, K.K. Boloor, K.S. Sane, S.S. Ghaskadbi and R.D. Lele, 2004. Free radicals and antioxidants in human health: Current status and future prospects. J. Assoc. Physicians India, 52: 794-804.

Dike, I.P., 2014. Importance of designer eggs for the Nigerian population. Afr. J. Agric. Res., 9: 1770-1773.

Dong, L.F., E. Swettenham, J. Eliasson, X.F. Wang and M. Gold et al., 2007. Vitamin E analogues inhibit angiogenesis by selective induction of apoptosis in proliferating endothelial cells: The role of oxidative stress. Cancer Res., 67: 11906-11913.

Farrell, D.J., 1998. Enrichment of hen eggs with n-3 long-chain fatty acids and evaluation of enriched eggs in humans. Am. J. Clin. Nutr., 68: 538-544.

Ferrier, L.K., L.J. Caston, S. Leeson, J. Squires, B.J. Weaver and B.J. Holub, 1995. Alpha-Linolenic acid- and docosahexaenoic acid-enriched eggs from hens fed flaxseed: Influence on blood lipids and platelet phospholipid fatty acids in humans. Am. J. Clin. Nutr., 62: 81-86.
Fisinin, V.I., T.T. Papazyan and P.F. Surai, 2009. Producing selenium-enriched eggs and meat to improve the selenium status of the general population. Crit. Rev. Biotechnol., 29: 18-28.

Fredriksson, S., K. Elwinger and J. Pickova, 2006. Fatty acid and carotenoid composition of egg yolk as an effect of microalgae addition to feed formula for laying hens. Food Chem., 99: 530-537.

Gilbert, D.L., 1981. Oxygen and Living Processes: An Interdisciplinary Approach. Springer-Verlag, New York, ISBN-13: 9783540905547 , Pages: 401.

Gilbert, L.C., 2000. The functional food trend: What's next and what Americans think about eggs. J. Am. Coll. Nutr., 19: 507S-512S.

Gjorgovska, N. and K. Filev, 2010. Enriching the hen eggs with selenium. Proceedings of the 1st International Agronomic Scientific Symposium on Agrosym, (AS'10), Jahorina, East Sarajevo, pp: 493-498.

Gjorgovska, N., F. Kiril, L. Vesna and K. Tosho, 2012. The effect of different levels of selenium in feed on egg production, egg quality and selenium content in yolk. Lucrari Stiintifice Seria Zootehnie, 57: 270-274.

Gopi, M., K. Karthik, H.V. Manjunathachar, P. Tamilmahan and M. Kesavan et al., 2014. Essential oils as a feed additive in poultry nutrition. Adv. Anim. Vet. Sci., 2: 1-7.

Goswami, S.K. and D.K. Das, 2009. Resveratrol and chemoprevention. Cancer Lett., 284: 1-6.

Grashorn, M.A. and W. Steinberg, 2002. Deposition rate of canthaxanthin in egg yolks. Arch. Geflugelk., 66: $258-262$

Guyonnet, V., 2011. Strategic Planning for the Development of the Egg Nutraceutical Industry. In: Improving the Safety and Quality of Eggs and Egg Products: Egg Safety and Nutritional Quality, Van Immerseel, F., Y. Nys and M. Bain (Eds.). Woodhead Publishing, Cambridge, UK., pp: 374-399.

Halliwell, B. and J.M.C. Gutteridge, 1985. Free Radicals in Biology and Medicine. Oxford University Press, Oxford, UK.

Hasler, C.M., 2000. The changing face of functional foods. J. Am. Coll. Nutr., 19: 499S-506S.

Hattingh, Z., C.M. Walsh and O.O. Oguntibeju, 2008. Energy and macronutrients intake in two age groups of black South African women. Am. J. Food Technol., 3: 109-117.

Herron, K.L. and M.L. Fernandez, 2004. Are the current dietary guidelines regarding egg consumption appropriate? J. Nut., 134: 187-190.

Howell, W.H., D.J. McNamara, M.A. Tosca, B.T. Smith and J.A. Gaines, 1997. Plasma lipid and lipoprotein responses to dietary fat and cholesterol: A meta-analysis. Am. J. Clin. Nutr., 65: 1747-1764.

Hu, F.B., M.J. Stampfer, J.E. Manson, E.B. Rimm and A. Wolk et al., 1999. Dietary intake of alpha-linolenic acid and risk of fatal ischemic heart disease among women. Am. J. Clin. Nutr., 69: 890-897. 
Invernizzi, G., A. Agazzi, M. Ferroni, R. Rebucci and A. Fanelli et al., 2013. Effects of inclusion of selenium-enriched yeast in the diet of laying hens on performance, eggshell quality and selenium tissue deposition. Italian J. Anim. Sci., Vol. 12.

Jacob, R.A. and G. Sotoudeh, 2002. Vitamin C function and status in chronic disease. Nutr. Clin. Care, 5: 66-74.

Jang, I., Y. Ko, S. Kang, S. Kim and M. Song et al., 2014.Effects of dietary lutein sources on lutein-enriched egg production and hepatic antioxidant system in laying hens. J. Poult. Sci., 51: 58-65.

Jezewska-Zychowicz, M., 2009. Impact of beliefs and attitudes on Young consumers' willingness to use functional food. Polish J. Food Nutr. Sci., 59: 183-187.

Jia, W., B.A. Slominski, W. Guenter, A. Humphreys and O. Jones, 2008. The effect of enzyme supplementation on egg production parameters and omega-3 fatty acid deposition in laying hens fed flaxseed and canola seed. Poult. Sci., 87: 2005-2014.

Juturu, V., 2008. Omega-3 fatty acids and the cardiometabolic syndrome. J. CardioMetab. Syndrome, 3: 244-253.

Kaminska, B.Z., R. Gasior and B. Skraba, 2001. Modification of polyunsaturated fatty acid contents in yolk lipids using various cereals and blended animal fat in hens' diets. J. Anim. Feed Sci., 10: 255-260.

Kang, D.K., S.I. Kim, C.H. Cho, Y.H. Yim and H.S. Kim, 2003. Use of lycopene, an antioxidant carotinoid, in laying hens for egg yolk pigmentation. Asian Aust. J. Anim. Sci., 16: 1799-1803.

Kassis, N., S.R. Drake, S.K. Beamer, K.E. Matak and J. Jaczynski, 2010. Development of nutraceutical egg products with omega-3-rich oils. Food Sci. Technol., 43: 777-783.

Khan, R.U., S. Naz, Z. Nikousefat, M. Selvaggi, V. Laudadio and V. Tufarelli, 2012a. Effect of ascorbic acid in heat-stressed poultry. World's Poult. Sci. J., 68: 477-490.

Khan, R.U., S. Naz, Z. Nikousefat, V. Tufarelli, M. Javdani, M.S. Qureshi and V. Laudadio, 2012b. Potential applications of ginger (Zingiber officinale) in poultry diets. World's Poult. Sci. J., 68: 245-252.

Kilgour, J. and R. Roberts, 2014. Pathophysiological Roles of Reactive Oxygen and Nitrogen Species. In: Systems Biology of Free Radicals and Antioxidants, Ismail, L. (Ed.). Springer, Berlin, Heidelberg, ISBN-13: 978-3-642-30018-9, pp: 171-206.

Kim, S., M.J. Lee, J. Hong, C. Li and T.J. Smith et al., 2000. Plasma and tissue levels of tea catechins in rats and mice during chronic consumption of green tea polyphenols. Nutr. Cancer, 37: 41-48.

Kirubakaran, A., D. Narahari, T.E. Valavan and A.S. Kumar, 2011. Effects of flaxseed, sardines, pearl millet and holy basil leaves on production traits of layers and fatty acid composition of egg yolks. Poult. Sci., 90: 147-156.

Kovacs-Nolan, J., J.W. Zhang, S. Hayakawa and Y. Mine, 2000. Immunochemical and structural analysis of pepsin-digested egg white ovomucoid. J. Agric. Food Chem., 48: 6261-6266.
Krinsky, N.I. and E.J. Johnson, 2005. Carotenoid actions and their relation to health and disease. Mol. Aspects Med., 26: 459-516.

Kuhnle, G.G.C., C. Dell'Aquila, S.M. Aspinall, S.A. Runswick, A.A. Mulligan and S.A. Bingham, 2008. Phytoestrogen content of foods of animal origin: Dairy products, eggs, meat, fish and seafood. J. Agric. Food Chem., 56: 10099-10104.

Lambert, J.D., J. Hong, G.Y. Yang, J. Liao and C.S. Yang, 2005. Inhibition of carcinogenesis by polyphenols: Evidence from laboratory investigations. Am. J. Clin. Nutr., 81: 284S-291S.

Lau, T.C., M.W. Chan, H.P. Tan and C.L. Kwek, 2013. Functional food: A growing trend among the health conscious. Asian Soc. Sci., 9: 198-208.

Laudadio, V. and V. Tufarelli, 2010. Treated fava bean (Vicia faba var. minor) as substitute for soybean meal in diet of early phase laying hens: Egg-laying performance and egg quality. Poult. Sci., 89: 2299-2303.

Laudadio, V. and V. Tufarelli, 2011. Influence of substituting dietary soybean meal for dehulled-micronized lupin (Lupinus albus cv. Multitalia) on early phase laying hens production and egg quality. Livestock Sci., 140: 184-188.

Laudadio, V., E. Ceci, N.M.B. Lastella, M. Introna and V. Tufarelli, 2014. Low-fiber alfalfa (Medicago sativa L.) meal in the laying hen diet: Effects on productive traits and egg quality. Poult. Sci., 93: 1868-1874.

Leeson, S. and L. Caston, 2004. Enrichment of eggs with lutein. Poult. Sci., 83: 1709-1712.

Leeson, S. and L. J. Caston, 2003. Vitamin enrichment of eggs. J. Applied Poult. Res., 12: 24-26.

Leoncini, E., C. Prata, M. Malaguti, I. Marotti and A. Segura-Carretero et al., 2012. Phytochemical profile and nutraceutical value of old and modern common wheat cultivars. PLoS ONE, Vol. 7. 10.1371/ journal.pone.0045997

Leskanich, C.O. and R.C. Noble, 1997. Manipulation of the $n-3$ polyunsaturated fatty acid composition of avian eggs and meat. World's Poult. Sci. J., 53: 155-183.

Levy, J., E. Bosin, B. Feldman, Y. Giat, A. Miinster, M. Danilenko and Y. Sharoni, 1995. Lycopene is a more potent inhibitor of human cancer cell proliferation than either $\alpha$-carotene or $\beta$-carotene. Nutr. Cancer., 24: 257-266.

Lewis, N.M., S. Seburg and N.L. Flanagan, 2000. Enriched eggs as a source of N-3 polyunsaturated fatty acids for humans. Poult. Sci., 79: 971-974.

Lin, C.Y., W.C. Hsiao, D.E. Wright, C.L. Hsu, Y.C. Lo, G.S.W. Hsu and C.F. Kao, 2013. Resveratrol activates the histone $\mathrm{H} 2 \mathrm{~B}$ ubiquitin ligase, RNF20, in MDA-MB-231 breast cancer cells. J. Funct. Foods, 5: 790-800.

Liu, R.H., 2007. Whole grain phytochemicals and health. J.Cereal Sci.,46: 207-219.

Liu, X., H.L. Zhao, S. Thiessen, J.D. House and P.J.H. Jones, 2010. Effect of plant sterol-enriched diets on plasma and egg yolk cholesterol concentrations and cholesterol metabolism in laying hens. Poult. Sci., 89: 270-275. 
Mazalli, M.R., D.E. Faria, D. Salvador and D.T. Ito, 2004. A comparison of the feeding value of different sources of fats for laying hens: 1. Performance characteristics. J. Applied Poult. Res., 13: 274-279.

Moeller, S.M., P.F. Jacques and J.B. Blumberg, 2000. The potential role of dietary xanthophylls in cataract and age-related macular degeneration. J. Am. Coll. Nutr., 19: $522 \mathrm{~S}-527 \mathrm{~S}$.

Mohiti-Asli, M., F. Shariatmadari, H. Lotfollahian and M.T. Mazuji, 2008. Effects of supplementing layer hen diets with selenium and vitamin E on egg quality, lipid oxidation and fatty acid composition during storage. Can. J. Anim. Sci., 88: 475-483.

Narahari, D., A. Kirubakaran and R. Kumararaj, 2004. Influence of herbal enriched functional eggs consumption on serum lipid profile in humans. Proceedings of the 22nd World Poultry Congress, June 8-13, 2004 , Istanbul, Turkey.

Nash, D.M., R.M.G. Hamilton, K.A. Sanford and H.W. Hulan, 1996. The effect of dietary menhaden meal and storage on the omega- 3 fatty acids and sensory attributes of egg yolk in laying hens. Can. J. Anim. Sci., 76: 377-384.

Nezhad, Y.E., N.M. Sis, H.A. Shahryar, M.R. Dastouri, A.A. Golshani, A. Tahvildarzadeh and K.A. Najafyan, 2008. The effects of combination of citric acid and microbial phytase on the egg quality characteristics in laying hens. Asian J. Anim. Vet. Adv., 3: 293-297.

Niemiec, J., M. Stepinska, E. Swierczewska, J. Riedel and A. Boruta, 2001. The effect of storage on egg quality and fatty acid content in PUFA-enriched eggs. J. Anim. Feed Sci., 10: 267-272.

Nimalaratne, C., D. Lopes-Lutz, A. Schieber and J. Wu, 2011. Free aromatic amino acids in egg yolk show antioxidant properties. Food Chem., 129: 155-161.

Padayatty, S.J., H.D. Riordan, S.M. Hewitt, A. Katz, J.L. Hoffer and M. Levine, 2006. Intravenously administered vitam in $\mathrm{C}$ as cancer therapy: Three cases. Can. Med. Assoc. J., 174: 937-942.

Pal, D. and P. Verma, 2013. Flavonoids: A powerful and abundant source of antioxidants. Int. J. Pharm. Pharmaceut. Sci., 5: 95-98.

Pandithurai, M. and S. Murugesan, 2014. Free radical scavenging activity of methanolic extract of brown alga Spatoglossum asperum. J. Chem. Pharm. Res., 6: 128-132.

Papp, L.V., J. Lu, A. Holmgren and K.K. Khanna, 2007. From selenium to selenoproteins: Synthesis, identity and their role in human health. Antioxidant Redox Signaling, 9: 775-806.

Payet, M., M.H. Esmail, E. Polichetti, G. Le Brun and L. Adjemout et al., 2004. Docosahexaenoic acid-enriched egg consumption induces accretion of arachidonic acid in erythrocytes of elderly patients. Br. J. Nutr., 91: 789-796.

Pham-Huy, L.A, H. He and C. Pham-Huy, 2008. Free radicals, antioxidants in disease and health. Int. J. Biomed. Sci., 4: 89-96.
Pophaly, S.D., Poonam, P. Singh, H. Kumar, S.K. Tomar and R. Singh, 2014. Selenium enrichment of lactic acid bacteria and bifidobacteria: A functional food perspective. Trends Food Sci. Technol., 39: 135-145.

Poudyal, H., S. Panchal and L. Brown, 2010. Comparison of purple carrot juice and $\beta$-carotene in a high-carbohydrate, high-fat diet-fed rat model of the metabolic syndrome. Br. J. Nutr., 104: 1322-1332.

Powers, S., W.B. Nelson and M.B. Hudson, 2011. Exerciseinduced oxidative stress in humans: Cause and consequences. Free Radical Biol. Med., 51: 942-950.

Qureshi, A.I., F.K. Suri, S. Ahmed, A. Nasar, A.A. Divani and J.F. Kirmani, 2007. Regular egg consumption does not increase the risk of stroke and cardiovascular diseases. Med. Sci. Monitor: Int. Med. J. Exp. Clin. Res., 13: CR1-CR8.

Rahal, A., A. Kumar, V. Singh, B. Yadav, R. Tiwari, S. Chakraborty and K. Dhama, 2014. Oxidative stress, prooxidants and antioxidants: The interplay. BioMed Res. Int. 10.1155/2014/761264

Raj, P.M., D. Narahari and N.S. Balaji, 2013. Production of eggs with enriched nutritional value (designer eggs) using feeds containing herbal supplements. Int. J. Vet. Sci., 2: 99-102.

Remanan, M.K. and J. Wu, 2014. Antioxidant activity in cooked and simulated digested eggs. Food Funct., 5: 1464-1474.

Ren, Y., T.I. Perez, M.J. Zuidhof, R.A. Renema and $\mathrm{J}$. Wu, 2013. Oxidative stability of omega-3 polyunsaturated fatty acids enriched eggs. J. Agric. Food Chem., 61: 11595-11602.

Rymer, C. and D.I. Givens, 2005. N-3 fatty acid enrichment of edible tissue of poultry: A review. Lipids, 40: 121-130.

Samman, S., F.P. Kung, L.M. Carter, M.J. Foster, Z.I. Ahmad, J.L. Phuyal and P. Petocz, 2009. Fatty acid composition of certified organic, conventional and omega-3 eggs. Food Chem., 116: 911-914.

Sawant, P.M., R. Tiwari, M.Y. Wani and K. Dhama, 2012. Functional and designer foods/products of animal origin. Processed Food Ind., 1: 49-55.

Schiavone, A. and A.C. Barroeta, 2011. Egg Enrichment with Vitamins and Trace Minerals. In: Improving the Safety and Quality of Eggs and Egg Product: Egg Safety and Nutritional Quality, Van Immerseel, F., Y. Nys and M. Bain (Eds.). Vol. 2, Woodhead Publishing, Cambridge, UK., pp: 289-320.

Shi, J. and M. le Maguer, 2000. Lycopene in tomatoes: Chemical and physical properties affected by food processing. Crit. Rev. Biotechnol., 20: 293-334.

Simopoulos, A.P., 1991. Omega-3 fatty acids in health and disease and in growth and development. Am. J. Clin. Nutr., 54: 438-463.

Singh, V.P. and N. Sachan, 2010. Designer eggs: A smart approach for health conscious persons. Poult. Planner, 11: 21-23. 
Singh, V.P., V. Pathak and K.V. Akhilesh, 2012. Modified or enriched eggs: A smart approach in egg industry: A review. Am. J. Food Technol., 7: 266-277.

Skrivan, M. and M. Englmaierova, 2014. The deposition of carotenoids and $\alpha$-tocopherol in hen eggs produced under a combination of sequential feeding and grazing. Anim. Feed Sci. Technol., 190: 79-86.

Smoliga, J.M., J.A. Baur and H.A. Hausenblas, 2011. Resveratrol and health-a comprehensive review of human clinical trials. Mol. Nutr. Food Res., 55: 1129-1141.

Sohal, R.S. and R. Weindruch, 1996. Oxidative stress, caloric restriction and aging. Science, 273: 59-63.

Stadelman, W.J., 1999. The incredibly functional egg. Poult. Sci., 78: 807-811.

Stadelman, W.J., D. Newkirk and W.J. Cotterill, 1995. Egg Science and Technology. 4th Edn., CRC Press, New York, ISBN-13: 978-1560228554, Pages: 5491.

Sujatha, T. and D. Narahari, 2011. Effect of designer diets on egg yolk composition of White Leghorn hens. J. Food Sci. Technol., 48: 494-497.

Surai, P.F., 2000. Organic selenium: Benefits to animals and humans, a biochemists view. Proceedings of the Alltech's 16th Annual Symposium, (AAS'00), Thrumpton, Nottingham, pp: 205-260.

Surai, P.F. and N.H.C. Sparks, 2001. Designer eggs: From improvement of egg composition to functional food. Trends Food Sci. Technol., 12: 7-16.

Surai, P.F. and V.I. Fisinin, 2014. Selenium in poultry breeder nutrition: An update. Anim. Feed Sci. Technol., 191: 1-15.

Traber, M.G., 2007. Vitamin E regulatory mechanisms. Annu. Rev. Nutr., 27: 347-362.

Tufarelli, V. and V. Laudadio, 2011. Dietary supplementation with selenium and vitamin $\mathrm{E}$ improves milk yield, composition and rheological properties of dairy Jonica goats. J. Dairy Res., 78: 144-148.
Unlu, N.Z., T. Bohn, D.M. Francis, H.N. Nagaraja, S.K. Clinton and S.J. Schwartz, 2007. Lycopene from heat-induced cis-isomer-rich tomato sauce is more bioavailable than from all-trans-rich tomato sauce in human subjects. Br. J. Nutr., 98: 140-146.

Van Elswyk, M.E., A.R. Sams and P.S. Hargis, 1992. Composition, functionality and sensory evaluation of eggs from hens fed dietary menhaden oil. J. Food Sci., 57: 342-344.

Venardos, K.M., A. Perkins, J. Headrick and D.M. Kaye, 2007. Myocardial ischemia-reperfusion injury, antioxidant enzyme systems and selenium: A review. Curr. Med. Chem., 14: 1539-1549.

Voutilainen, S., T. Nurmi, J. Mursu and T.H. Rissanen, 2006. Carotenoids and cardiovascular health. Am. J. Clin. Nutr., 83: 1265-1271.

Weggemans, R.M., P.L. Zock and M.B. Katan, 2001. Dietary cholesterol from eggs increases the ratio of total cholesterol to high-density lipoprotein cholesterol in humans: Ameta-analysis. Am. J. Clin. Nutr., 73: 885-891.

Wojcik, M., I. Burzynska-Pedziwiatr and L.A. Wozniak, 2010. A review of natural and synthetic antioxidants important for health and longevity. Curr. Med. Chem., 17: 3262-3288.

Yardebi, H. and G. Turkay, 2008. The Effects of vitam in E on the antioxidant system, egg production and egg quality in heat stressed laying hens. Turkey J. Anim. Sci., 32: $319-325$.

Zhang, J., R.G. Munger, N.A.West, D.R. Cutler, H.J. Wengreen and C.D. Corcoran, 2006. Antioxidnat intake and risk of osteoporotic hip fracture in Utah: and effect modified by smoking status. Am. J. Epidemiol., 163: 9-17.

Zhang, M., S. Altuwaijri and S. Yeh, 2004. RRR- $\alpha$-tocopheryl succinate inhibits human prostate cancer cell invasiveness. Oncogene, 23: 3080-3088. 